http://dx.doi.org/10.35381/r.k.v6i12.1290

\title{
Desarrollo y gestión de riesgos del Sector Asegurador en el Ecuador
}

Development and risk management of the Insurance Sector in Ecuador

\author{
Jhoana Pricila Segarra-Cobos \\ jhoanap.segarra@est.ucacue.edu.ec \\ Universidad Católica de Cuenca, Cuenca \\ Ecuador \\ https://orcid.org/0000-0001-6202-0136 \\ Dayana Yasmín Murillo-Párraga \\ dayana.murillo@ucacue.edu.ec \\ Universidad Católica de Cuenca, Cuenca \\ Ecuador \\ https://orcid.org/0000-0001-9652-4535
}

Recepción: 15 de marzo 2021

Revisado: 15 de mayo 2021

Aprobación: 15 de junio 2021

Publicación: 01 de julio 2021 


\title{
RESUMEN
}

El mercado asegurador ayuda a fomentar el ahorro, la financiación, inversiones a largo plazo que aumenta el empleo y productividad en el sector de seguros en nuestro país, en el año 2020 existe una disminución en el monto total de siniestros pagados por las aseguradoras en términos generales, pero en los ramos de vida se ha visto un incremento de reclamos pagados, siendo una de las causas la coyuntura mundial de la pandemia generada por el COVID-19, ante la situación descrita de las aseguradoras el objetivo principal es proponer un plan de negocios dado que el panorama cambió notablemente para el sector asegurador. La investigación es de tipo descriptiva con diseño no experimental. Existe un impacto COVID-19 muy alto debido a cambios en sus ingresos, aumento en cargas de trabajo, teletrabajo, reducción de sueldos, despidos y/o suspensión de actividades hechos que generan graves efectos en los hábitos de los hogares.

Descriptores: Operación administrativa; gestión de riesgos; toma de decisiones. (Tesauro de la UNESCO, 2019).

\begin{abstract}
The insurance market helps to promote savings, financing, long-term investments that increase employment and productivity in the insurance sector in our country, in 2020 there is a decrease in the total amount of claims paid by insurers in terms general, but in the life lines there has been an increase in paid claims, one of the causes being the global situation of the pandemic generated by COVID-19, given the described situation of the insurers the main objective is to propose a plan of business as the outlook changed significantly for the insurance sector. The research is descriptive with a non-experimental design. There is a very high COVID-19 impact due to changes in their income, increase in workloads, telework, reduction of salaries, layoffs and / or suspension of activities that have serious effects on household habits.
\end{abstract}

Descriptors: Management operations; risk management; decision making. (UNESCO Thesaurus, 2019). 


\section{INTRODUCCIÓN}

El mercado asegurador tiene un rol muy importante a nivel mundial, ya que ayuda al crecimiento económico y financiero de los países, así mismo, ayuda a fomentar el ahorro, la financiación, inversiones a largo plazo que aumenta el empleo y productividad en el sector de seguros, la venta de pólizas constituye una herramienta económica para hacer frente a los riesgos al momento de activar coberturas por causa de algún siniestro, pues adquirirlos es proteger el patrimonio familiar ante posibles eventos fortuitos que generen pérdida económica, es de importancia social que beneficia a personas, corporaciones, empresas y al estado (Cevallos-Villacis, 2012).

Como se pudo ver anteriormente el mercado de seguros es una gran herramienta para poder lograr el desarrollo de una economía en los países, más aún, los que están en desarrollo y para poder lograrlo se debe conocer la realidad de la nación, con esto, se procederá a realizar una breve descripción y conocer que tan fuerte es el mercado asegurador dentro de la económica nacional.

En nuestro país aún no existe la cultura de adquirir un seguro para respaldar nuestros bienes y la vida, de todo tipo de siniestros, incluso de los desastres naturales, su capacidad para adquirir es reducida, a pesar de todo esto las aseguradoras cuentan con la solvencia para poder afrontar todo tipo de siniestros como fue el terremoto ocurrido el 16 de abril del 2016, donde las compañías y reaseguros lograron cubrir grandes pérdidas sin tener mayor afectación (Bermudez-Barrezueta, 2018). Cabe mencionar que las compañías aseguradoras ecuatorianas han venido manteniéndose en constante crecimiento con los cambios e innovaciones de cada una de las compañías aseguradoras, en la creación de nuevos productos y servicios en los ramos más importantes que son de vida y generales (Saltos, 2016).

En el país existen 30 compañías de seguros de las cuales 25 comercializan el ramo de Vida, dentro de estas existe también compañías que comercializan ramos generales y Asistencia Médica, siendo el ente encargado de su control la Superintendencia de Compañías, Valores y Seguros. La Prima Neta Emitida en el año 2020 dentro del 
mercado asegurador ascendió a la suma de \$1.695.839.091,62 de este valor el 30.13\% corresponde a la prima neta emitida en el ramo de vida, cabe indicar que la participación del ramo de vida dentro del mercado asegurador es uno de los más grandes y el $69.87 \%$ restante de la prima neta emitida corresponde a ramos generales y asistencia médica, estos tienen sub ramos los cuales generan prima neta (accidentes personales, incendio, vehículos, rotura de maquinaria, responsabilidad civil, lucro cesante, entre otros. (Superintendencia de Compañias, Valores y Seguros, 2020).

El ramo de vida en el año 2020 tuvo como resultado técnico $\$ 45.026 .158,88$ contra el año 2019 que fue de $\$ 141.914 .865,78$ generándose una reducción del $68.27 \%$, el resultado se da debido al incremento de siniestros del año 2020 que fue de $\$ 109.975 .847,45$ (49.22\%) en comparación con el año anterior, considerando que los siniestros pagados en todo el mercado asegurador durante el 2020 fue de $\$ 760.708 .160,88$ de esto el 43.83\% corresponden a los ramos de vida, en cambio en el año 2019 con $\$ 769.190 .821,76$ siniestros pagados apenas el $29.05 \%$ fue por el ramo de vida. Como se puede observar en el año 2020 existe una disminución en el monto total de siniestros pagados por las aseguradoras en términos generales, pero en los ramos de vida se ha visto un notorio incremento de reclamos pagados, siendo una de las posibles causas la coyuntura mundial de la pandemia generada por el COVID-19 (Superintendencia de Compañias, Valores y Seguros, 2020).

Ante la situación descrita de las aseguradoras, el objetivo principal es proponer un plan de negocios que permita reducir el impacto económico negativo de las mismas, dado que el panorama cambió notablemente para el sector asegurador, llegando afectar drásticamente nuestra economía, las ventas de las pólizas disminuyeron a gran escala, el pago de primas de muchos clientes no pudo cubrirse, los resultados negativos que se tienen por el pago de siniestros especialmente en el ramo de vida y asistencia médica por la contingencia del COVID-19 (El Comercio , 2020). Por esta razón se ha visto la importancia de elaborar un plan adecuado de negocios que contemple impactos locales que serán de gran ayuda hacia todo el mercado asegurador. 


\section{Referencial Teórico}

\section{Evolución del mercado asegurador y el análisis de su impacto económico}

Se debe considerar que el ser humano, es un ser evolutivo el cual ha tenido que pasar por varias etapas riesgosas para lograr su evolución, el riesgo es inherente a los seres humanos, por lo cual los individuos desde la antigüedad han querido vivir sin mayores preocupaciones y tratar de brindar un respaldo a sus generaciones, pensando siempre en como algún evento incierto pudiera terminar con estos sueños. Fruto de este problema las personas inventaron un seguro que en un concepto básico lo podemos definir como un contrato o póliza que es un vínculo jurídico a través del cual el asegurado paga una prima a la compañía de seguros y a cambio este se obliga a indemnizar a la otra parte en caso de que ocurra un siniestro (León-Alvear \& León-Alvear, 2019). Es por eso que, al hablar de una póliza de seguros, las personas lo contextualizan como un gasto, un lujo, o lo miran como un servicio que se lo adquiere en cualquier momento, o si su perfil frente al riesgo es opuesto pueden verse como una herramienta de inversión que provee seguridad financiera, patrimonial ante futuros riesgos (Coronel-Pérez \& Buñay-Cantos, 2018).

Desde épocas muy remotas siempre ha existido la inseguridad de pérdida económica, por esta razón la teoría más aceptada del Seguro surgió como un fondo de un grupo de transportistas marítimo que tuvieron la necesidad económica de protección cuando existía pérdida, antiguamente cansados y/o preocupados de perder mercaderías y barcos por las inclemencias del mar, optaron por colaborar con un importe económico de cada transportista y en caso de ocurrir algún evento en el que se perjudicara uno de los participantes, este se vería resarcido por el importe realizado por los demás participantes. Esta práctica antigua tuvo acogida luego de ver su eficacia ante siniestros y generar beneficios económicos, posterior a esto se adaptó a las necesidades y llegó a consolidarse como una herramienta fundamental para hacer frente a siniestros que pueden afectar el patrimonio de las personas (Manzano-Martos, 2012). 
Es por eso que el seguro dio un giro de gran adaptación, evolución y transformación a nivel mundial, hasta establecerse como un gran mercado el cual es capaz de hacer frente a eventualidades adversas e inesperadas (Curiosfera, 2021). Los Seguros en el Ecuador están legislados por la Ley General de Seguros, ha ido creciendo conforme las necesidades de la sociedad, mientras crece la población aumenta la venta de los seguros, se ha tornado una herramienta de negocios desde siglos atrás, por eso la manera más común que las personas tienen para disminuir el riesgo a perder un bien debe serlo comprando un seguro, de hecho, existen las siguientes personas que intervienen en la contratación del seguro (Argudo-Tello, et al. 2019).

La principal función del seguro es ahorrar para hacer futuras inversiones, quitando el miedo a las personas a invertir en sus emprendimientos o compras de activos patrimoniales que cuestan mucho dinero o cuando el patrimonio es pequeño pues el seguro es un respaldo que garantiza protección. Con lo anteriormente indicado se necesita hacer un análisis del mercado de seguros ya que no solo es de interés de la aseguradora también es de la sociedad para conocer el impacto que tenemos dentro del sector asegurador como potencia económica y de esta manera posibilitar la creación de otros seguros que beneficie obtener mejores resultados (Jouvin-Aráuz \& RodríguezMurillo, 2008).

Una compañía de seguros es una persona jurídica que debe estar legalmente constituida, su principal actividad económica es otorgar a terceras personas y corporaciones coberturas de riesgos que afecten su economía, es decir, un riesgo asegurable cuando ocurra un siniestro. Se podría decir también que las aseguradoras cumplen dos funciones importantes que son la transferencia del riesgo ya sean situaciones económicas o personales que ayuda al asegurado a disminuir su miedo de perderlo todo y la otra es la parte financiera; ya que las compañías de seguros son importantes inversores que contribuyen en un mercado de capital, promoviendo la estabilidad a través de inversiones a largo plazo y sobre todo educando a la buena práctica del ahorro (Sabater-Castro, 2017). 
Así mismo, un siniestro genera pérdida para la sociedad en general no solo materiales si no afecta notablemente la parte financiera, es aquí donde actúa el asegurador, cuyo objetivo primordial es cubrir dicha pérdida, por ende, cuando se protege su economía se genera una competitividad y permite que exista el crecimiento y desarrollo de manera personal y empresarial, de hecho, estas fueron creadas para ayudar a disminuir en gran parte, hechos que pueden ocurrir de manera súbita que no dependa de la voluntad del asegurado, en este contexto son una garantía para empezar de nuevo, haciendo énfasis que las aseguradoras son las que se encargan de indemnizar a sus asegurados por el daño ocurrido, bajo parámetros escritos netamente en el contrato (Vidal-Beltrán, et al. 2019).

Con esta aclaración el asegurador no solo actúa en el momento de un siniestro si no también son asesores para el cliente, pues deben tener personal netamente capacitado que identifique y tarifique técnicamente de manera correcta los riesgos, pactando así con un precio considerable que el asegurado debe pagar por proteger su riesgo, el precio en el sector de seguros se denomina prima, a mayor riesgo mayor prima a pagar. Sin embargo, haciendo énfasis lo que busca la aseguradora es maximizar su rentabilidad financiera.

Se podría decir también que la aseguradora tiene una clasificación muy amplia referente al ramo, se indica cómo; seguros de cosas se asegura en el caso de robo, incendio, vehículos y otros, seguro de personas gira alrededor de las personas para cuidar su integridad y su vida de algún accidente o enfermedad, seguro patrimonial cubre a terceras personas y el seguro de derechos puede ser el derecho a un crédito como el de caución (La Junta Bancaria, 2012).

Debe señalarse también por otra parte que una de las características especiales que tiene la aseguradora es que trabajan con capital propio y tienen la solvencia suficiente como para cubrir los siniestros, brindando de esta manera confianza a sus clientes. Las aseguradoras, a cambio de una parte de su prima en algunos casos trasladan el riesgo a otras compañías llamadas Reaseguradoras, para cubrir el siniestro en caso de existir, 
generando de esta manera tranquilidad para la compañía aseguradora y sus asegurados, disminuyendo el riesgo, generando liquidez, solvencia, créditos, insuficiencia en reservas técnicas, siendo este último un factor que puede afectar los resultados y generar pérdida económica o patrimonial de la entidad aseguradora.

El mercado asegurador tiene un papel fundamental dentro de la económica mundial pues contribuye al desarrollo financiero y al crecimiento económico de todos los países, siendo así que en las dos últimas décadas acelero el crecimiento de las compañías aseguradoras pues su prima neta emitida a nivel mundial incremento el 175\% (Outreville, 2012). En el Ecuador las compañías aseguradoras privadas son de gran importancia ya que están aportando de manera positiva al crecimiento económico y desarrollo de todo el país, razón primordial para culturizar a la sociedad de trasladar ese riesgo de pérdida a las aseguradoras, aportando toda la protección económica posible (León-Alvear \& León-Alvear, 2019).

El mercado asegurador ecuatoriano experimento diversos cambios legales, reglamentarios y políticos uno de esos cambios fue que en el año 2016 entro en vigencia la Ley Regulatoria del Poder de Mercado o Ley Antimonopolio dentro del Ecuador, en el que hacía referencia que los bancos no tenían que tener inversiones que no provengan de su actividad financiera, por tal razón algunos bancos tuvieron que vender sus compañías de seguros, con esto se pudo dar un gran avance para que mejore el mercado asegurador ya que esto permitió una competencia más equilibrada entre compañías, pues algunas se funcionaron y otras cerraron por no contar con capital suficiente para el giro del negocio que es de $8 \mathrm{M}$, en la actualidad su ente de control es la Superintendencia de Compañía, Valores y Seguros (Andrade-Granja, 2016). De esta manera, el país se ha mantenido en constante crecimiento dentro del mercado asegurador y se lo puede medir mediante el Producto Interno Bruto (PIB), La participación en primas netas emitidas en el año 2010 fue del 1,6\%, mientras que en el año 2020 fue del 1,7\% (Gestión, 2020), lo que significa que puede llegar a tener mayor crecimiento del mercado. 


\section{Plan de Negocios y su importancia en el crecimiento económico.}

Para conocer un plan de negocios y como actúa dentro del crecimiento económico, es importante entender primeramente que es un plan, un negocio y para qué sirve, por ende, el plan se entiende como un proceso que nos ayuda a fijar objetivos específicos y guiarnos de los mismos para cumplirlos (Viniegra, 2007). Por otra parte, un negocio es una actividad que se realiza con el objetivo de obtener dinero por la venta de bienes o la prestación de servicios (Moyano-Castillejo, 2015) de esto se deriva un plan de negocios que es un documento en el que se escriben todas las actividades comerciales, logísticas, financieras, etc. para obtener el dinero, logrando la satisfacción de las personas a quienes se dirige el negocio.

De esta forma el plan de negocios ayuda a obtener financiamiento con inversionistas, entidades bancarias, es un documento que indica que el negocio es rentable, es decir, es un proceso de planificación de cómo se realizan dichas actividades que servirán de plataforma principal para lograr el objetivo del negocio (Thomsen, 2009), también ayuda al empresario a utilizarlo como una guía que ayuda a la gestión de una idea, la misma que es analizada, validada y se termina con la entrega de un plan concluido (AndíaValencia \& Paucara-Pinto, 2013).

Para elaborar un plan de negocios lo más importante es la planificación, con esto lo que se permite hacer es identificar lo que necesita la empresa hacer para obtener beneficios, posterior a esto identifican la oportunidad o el problema del mercado relacionando con el producto, la oportunidad y de esta manera poder ofrecer dichos productos o servicios, este proceso es primordial ya que ayuda a encaminar con claridad el proceso para llegar al objetivo que es la venta y llamar la atención a nuevos accionistas y/o clientes dependiendo el caso (Koontz, et al. 2012).

El plan de negocios es un requisito muy importante dentro del actual entorno de una empresa y es también para los administradores, socios, inversionistas y entidades financieras, pues esta, es la propuesta fundamental para analizar la participación en el negocio o se cumplen las nuevas propuestas de una empresa ya encaminada, su 
estructura permite cubrir todos los departamentos del negocio facilitando el proceso de la planeación (Viniegra, 2007).

El plan de negocios surge de las necesidades insatisfechas de los usuarios, busca ampliar el mercado con ideas que permiten implementar la actividad empresarial, buscando que mejore la rentabilidad que es la meta más importante del plan que se pretende presentar (Moyano-Castillejo, 2015). Luego de haber analizado el tema del plan de negocios, se debe conocer cómo se apalanca en el crecimiento económico de un país, por lo mismo, entendamos de donde parte esta teoría y porque es importante en el desarrollo económico (Castelán-Valdivia \& Oros-Mendéz, 2011).

Muchos años atrás se lleva haciendo un estudio de los negocios que aportan el desarrollo económico a nivel mundial, permitiendo que se generen nuevos productos, servicios con mayor valor agregado para mejorar o innovar y así poder lograr un resultado positivo para la empresa, por esa razón los factores más importantes para lograrlo es la innovación, la tecnología y el emprendimiento, siendo los principales motores que aceleran el crecimiento de la economía y generan un alto potencial de desarrollo (Mayer-Granados, et al. 2020).

Las empresas que recién inician en el mercado, tienden a ir evolucionando con el paso de los años, su resultado o los frutos que obtenga no serán de manera inmediata ya que todo es mediante procesos, en el camino van a encontrar errores que deben mejorar para lograr estar siempre dentro de su competencia, con la experiencia adquirida sabrán incluso los gustos de sus consumidores, todo esto es mediante una sincronización, este camino lo ha seguido las grandes empresas que en la actualidad ocupan posiciones muy importantes dentro del mercado, incluso las más grandes tienen errores que deben ser corregidos para lograr sus propósitos obteniendo eficacia económica (Martínez-Cañon, 2015).

Hoy en día muchos países compiten por el crecimiento económico y su desarrollo haciendo a sus recursos, capital humano, materiales, como un enfoque encaminado a la globalización (Heizer \& Render, 2009). Las empresas que tienen mayor productividad 
generan mayor crecimiento y participación en el mercado, y las que tienen baja producción tienden a desaparecer, lo que genera una brecha baja entre empresa y no aportan al crecimiento del negocio (Primicias, 2019). En contexto el crecimiento económico hace referencia a los recursos que permiten mejorar el desarrollo humano y viceversa el mejoramiento del recurso humano permite importantes resultados en su crecimiento económico (Rivadeneira-Hermida, et al. 2021).

El aumento de la instrucción primaria, secundaria, tercer nivel de las personas hace que aumente la productividad de los negocios, pues con la educación utilizan técnicas, métodos innovadores y tecnológicos que ayudan a implementar estrategias, ideas que fortalecen el crecimiento de los negocios y generan como resultados de esto efectos positivos (Ranis \& Stewart, 2002).

Muchos de los empresarios en nuestro país generan un aspecto positivo dentro de la sociedad, pues ellos son los que ponen en marcha la economía nacional y local pues son personas que saben liderar y manejar correctamente la misma, generando capital a través de sus empresas, siendo ellos los primeros afortunados en esas ganancias, sin embargo, nos preguntamos ¿cómo ayudan a la sociedad?, claro está que son quienes generan fuentes de empleo, ingresos para las familias de los empleados, satisfacción a sus clientes por la adquisición o elaboración de un bien y/o servicio, contribuyen con el ingreso nacional con el pago de impuestos, todo esto hace que facilite el desarrollo económico de un país (Cardona, 2019).

En este contexto mencionamos que los negocios generan un papel importante y fundamental ya que ponen en marcha la economía de un país, generando empleo, auto empleo cuando se tratan de los emprendimientos, innovando en ideas e impulsando a empresas ya existentes a mejorar su estructura económica para de esta manera estar en el camino correcto y lograr el margen de rentabilidad esperado, ciertas empresas o negocios se centran más en las actividades comerciales que permiten tener mayor diversidad entre productos y servicios para ofertar generando de esta manera grandes cambios financieros y permitiendo estar dentro de la competencia (Zamora-Boza, 2018). 


\section{Gestión del Plan de Negocios como una herramienta importante para la sostenibilidad de las aseguradoras.}

La sostenibilidad es una necesidad que ayuda a ser mejor cada día más a un mundo entero, muchas de las empresas y personas están tratando de ponerlo en práctica para que de esta manera facilite el cambio financiero y a su vez el (ASG) Ambiental, Social y Gubernamental, considerando un mundo más verde que englobe y encaje en todos los ámbitos, desde un empleo que cumpla con las expectativas de calidad y donde los derechos humanos sean valorados, por lo tanto, la sostenibilidad para las empresas es crear objetivos para generar resultados positivos que nos permitan optimizar, tiempo y dinero.

Las compañías o empresas que muestran la ventaja o solución a la crisis que hoy en día enfrentan y de estas sacar el provecho al máximo son las que tienen una visión del futuro acertado y podrán cambiar sus modelos de negocios si así lo creyeran necesario para un futuro más sostenible. Para la UNESCO, las compañías aseguradoras no tienen mucho que ver con este plan de sostenibilidad sin embargo las mismas están comprometidas ya que para poder mantenerse en el mundo asegurador deben innovar y cambiar, en tendencias, costos, primas, servicios y otros (Sánchez-Sumelzo, 2012).

El concepto de sostenibilidad surge por los problemas que en la actualidad se dan a nivel mundial, es una oportunidad de cambio, es una forma vigente de hacer negocios para generar ganancias y de tratar de entender a la sociedad para lograr satisfacer cada una de las necesidades de la humanidad (Macedo, 2005), por consiguiente, la sostenibilidad es una frase que engloba textos muy complejos que no se puede resolver con una sola acción empresarial, cada una de las empresas tiene un reto con la modernización de su tecnología y sobre todo mejorando su eficacia operativa (Garzón-Castrillon \& IbarraMares, 2014).

La sostenibilidad abarca algunos principios en el sector asegurador y uno de ellos es tener en cuenta el ámbito social, ambiental y de gobernanza ASG para tomar decisiones en las aseguradoras e incentivar a todos los potenciales clientes y proveedores a tomar 
conciencia y exponer con transparencia y de manera pública estos principios. Incorporar dentro de la suscripción de los seguros la sostenibilidad en el caso de los medioambientales ya que al ser conocedores de los riesgos se puede ayudar a mitigarlos en gran parte ayudando a la sociedad (UNESPA , 2020).

Con esto lo que hace el sector asegurador es ofrecer bienes y/o servicios de acuerdo con las necesidades de cada una de las personas, creando alternativas que beneficien a la sociedad y a las empresas a obtener ventajas competitivas que puedan mantenerse dentro del mercado a largo plazo. No obstante, a esto, existe algunas cosas negativas que no permiten a la industria aseguradora a estar en todos los nichos del mercado pues los altos costos, la crisis, el desempleo ha venido generando grandes pérdidas, deben estar en una sola cuerda donde se puedan equilibrar las responsabilidades para que las aseguradoras puedan ingresar a todos los nichos de mercado con primas más accesibles y se aproveche asegurando todo lo que técnicamente esté al alcance.

Por consiguiente, existen empresas que trabajan con altos riesgos medioambientales, que amenazan su ámbito económico y social, sin embargo, no concientizan para tomar el seguro que les puede salvar de grandes pérdidas financieras que pueden llevarle a la quiebra de sus negocios. En consecuencia, de esto el sector asegurador es un factor que permite crear una nueva economía de servicios y es un puente que permite implementar la sostenibilidad empresarial, remplazando los productos antiguos por nuevos y con mejores estándares que permitan crecer mejorando o igualando los precios en el sector, con la capacidad de innovación y satisfacción de las necesidades (Ancos-Franco, 2015). La sostenibilidad está tomando importancia a pasos agigantados dentro de las empresas comerciales y financieras, ya que se ha generado un plan que permite crear procesos que ayudan a disminuir el riesgo ambiental social y gubernamental ASG, riesgos que tiene mayor relevancia en la política, la crisis financiera que hoy en día se atraviesa y los cambios demográficos han demostrado un impacto negativo en el sector financiero, la salud de las personas están siendo evaluados para poder crear un plan que ofrezca coberturas con montos asegurados que protejan las pérdidas de bienes y/o vida de las 
personas, las grandes aseguradoras están liderando este proceso de implementación de estrategias priorizando la toma de decisiones en la parte de la inversión y del aseguramiento. Mientras que las aseguradoras de los ramos generales son más vulnerables a los cambios meteorológicos que puede tener el país o en el mundo y en cambio los de vida son más débiles en el aspecto social y demográfico tomando todos estos aspectos para encaminar y dar prioridad a las estrategias ASB (GaldeanoLarisgoitia \& Pedraz-González, 2019).

Como se mencionó anteriormente los principios de sostenibilidad son una herramienta financiera que respalda las condiciones adversas, permitiendo a las aseguradoras analizar los sectores más vulnerables para propiciar su inclusión y darles acceso a un seguro con los costos más accesibles para que el beneficio se masifique a toda una población (Jiménez, 2020).

\section{MÉTODO}

La investigación fue de tipo descriptiva con diseño no experimental. El universo poblacional empleado son todas las personas mayores de 18 años dentro del territorio ecuatoriano, hemos utilizado el muestreo probabilístico que es una técnica de muestreo que utiliza pequeños grupos de una población y su selección es aleatoria, se obtiene fácilmente ya que no se toma datos de toda una población, en este caso aplicamos la siguiente formula:

$$
\mathrm{n}=\begin{gathered}
\mathrm{N}^{*} \mathrm{Z} 2 * \mathrm{p} * \mathrm{q} \\
\mathrm{d} 2 *(\mathrm{~N}-1)+\mathrm{Z} 2 * \mathrm{p} * \mathrm{q}
\end{gathered}
$$

En donde

$\mathrm{N}=$ Número total de la población o universo

$Z=$ coeficiente de seguridad, seleccione el coeficiente de seguridad de acuerdo con el margen de error

Z2 = Elevar Z al cuadrado (multiplicar el valor por sí mismo) 
$\mathrm{p}=$ proporción esperada, es un valor fijo

$q=1-p(1-0,05=0,95)$

$\mathrm{d}=$ precisión $=0,1$ (valor fijo)

$\mathrm{d} 2=$ Elevar $\mathrm{d}$ al cuadrado (multiplicar el valor por sí mismo)

$p^{*} q=$ Multiplicar el valor de $p$ por el valor de $q$

Con este cálculo se pudo determinar que, de un universo de 285 personas, se aplicó la encuesta a 203 personas. Se obtuvieron datos por medio de formularios en los que contenía un cuestionario de preguntas efectuados en Google (https://docs.google.com/forms) los mismos que fueron procesados mediante estadística descriptiva, esta información se tabuló en el programa de Microsoft Excel versión 2019 (Erazo \& Narváez, 2020).

\section{RESULTADOS}

Con los resultados obtenidos, procedemos a clasificar cada una de las variables.

Tabla 1.

Resultados Variables: Percepciones sobre el Seguro.

\begin{tabular}{|c|c|c|c|}
\hline Variable: Percepciones & Opciones de respuesta & Total & $\%$ \\
\hline \multirow{4}{*}{ Tipo de Seguro } & Ninguno & 74 & $36 \%$ \\
\hline & Personales (Vida, AP, Asistencia. Médica) & 60 & $30 \%$ \\
\hline & Generales(Vehículos, Incendio, Robo, Otros) & 30 & $15 \%$ \\
\hline & Generales y Personales & 39 & $19 \%$ \\
\hline \multirow{6}{*}{$\begin{array}{l}\text { Satisfacción del Seguro en } \\
\text { base a costos }\end{array}$} & Bueno & 65 & $32 \%$ \\
\hline & Malo & 6 & $3 \%$ \\
\hline & Muy Bueno & 21 & $10 \%$ \\
\hline & Ninguno & 68 & $33 \%$ \\
\hline & Pésimo & 3 & $1 \%$ \\
\hline & Regular & 40 & $20 \%$ \\
\hline \multirow{4}{*}{$\begin{array}{l}\text { Satisfacción del Seguro en } \\
\text { base a servicios }\end{array}$} & Bueno & 72 & $40 \%$ \\
\hline & Malo & 7 & $0 \%$ \\
\hline & Muy bueno & 22 & $10 \%$ \\
\hline & Ninguno & 64 & $30 \%$ \\
\hline
\end{tabular}


Revista Arbitrada Interdisciplinaria KOINONIA

Año VI. Vol VI. N 12. Julio - Diciembre. 2021

Hecho el depósito de Ley: FA2016000010

ISSN: 2542-3088

FUNDACIÓN KOINONIA (F.K). Santa Ana de Coro. Venezuela.

\begin{tabular}{llrr} 
& Pésimo & 4 & $0 \%$ \\
& Regular & 34 & $20 \%$ \\
\hline \multirow{3}{*}{$\begin{array}{l}\text { Percepción sobre cultura de } \\
\text { seguros }\end{array}$} & Alta & 17 & $8 \%$ \\
& Baja & 72 & $35 \%$ \\
& Muy alta & 2 & $1 \%$ \\
& Muy baja & 32 & $16 \%$ \\
& Regular & 80 & $39 \%$ \\
\hline
\end{tabular}

Elaboración: Los autores.

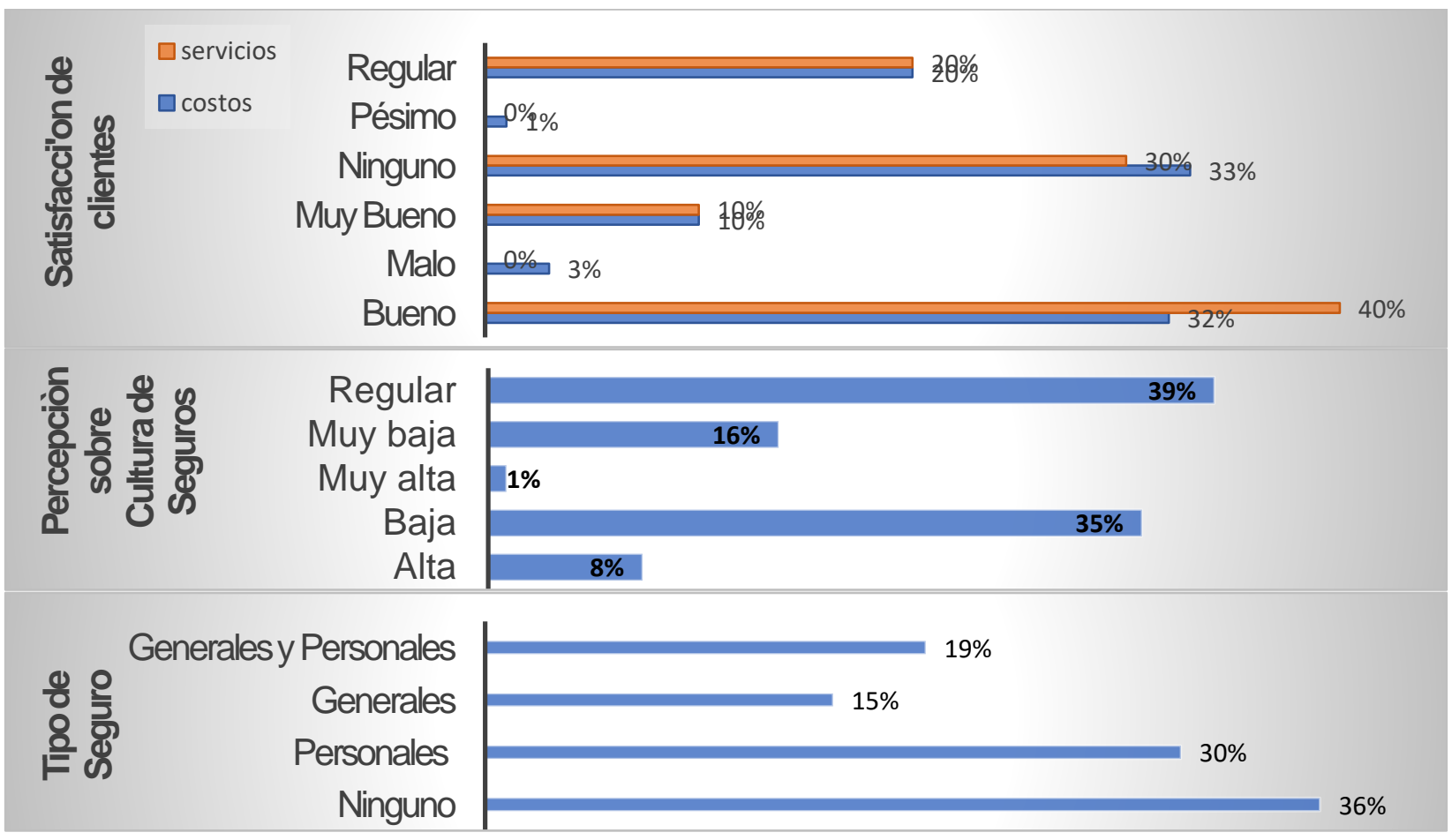

Figura 1. Resultados Variables: Percepciones sobre el Seguro. Elaboración: Los autores.

De acuerdo con la tabla y la figura 1, la mayoría de las personas encuestadas poseen un seguro diferente, sin embargo hay quienes indican que su satisfacción por el seguro referente a costos es regular y en cuanto a servicios es bueno, lo que quiere decir que el cliente no tiene toda la satisfacción de su seguro, por lo tanto, se puede utilizar como una 
herramienta que mejore esta situación, en cambio, la cultura en seguros con la muestra tomada indica que es muy baja, ya que existen personas que piensan que no puede ocurrirles un siniestro, por consiguiente, existe un gran nicho de mercado para ser explotado.

\section{Tabla 2.}

Resultados Variables: Impacto COVID-19.

\begin{tabular}{|c|c|c|c|}
\hline Variable: Impacto Covid-19 & Opciones de respuesta & Total & $\%$ \\
\hline \multirow{2}{*}{$\begin{array}{l}\text { Impacto sobre demanda de seguros a causa } \\
\text { del COVID-19 }\end{array}$} & $\mathrm{Si}$ & 133 & $66 \%$ \\
\hline & No & 70 & $34 \%$ \\
\hline \multirow{8}{*}{ Impacto COVID-19 Sobre Ingresos } & Ninguno & 20 & $10 \%$ \\
\hline & $\begin{array}{l}\text { Sigo trabajando de forma } \\
\text { presencial }\end{array}$ & 33 & $16 \%$ \\
\hline & Vacaciones Obligatorias & 3 & $1 \%$ \\
\hline & Reducción de Sueldo & 52 & $26 \%$ \\
\hline & Teletrabajo & 47 & $23 \%$ \\
\hline & Despedido/Suspensión de & & \\
\hline & Actividades & 32 & $16 \%$ \\
\hline & $\begin{array}{l}\text { Ha aumentado mi carga de } \\
\text { trabajo }\end{array}$ & 16 & $8 \%$ \\
\hline \multirow{4}{*}{ Situación Económica Actual de las Familias } & Buena & 67 & $33 \%$ \\
\hline & Mala & 20 & $10 \%$ \\
\hline & Pésima & 2 & $1 \%$ \\
\hline & Regular & 114 & $56 \%$ \\
\hline \multirow{4}{*}{ Situación Actual del País } & Buena & 1 & $0 \%$ \\
\hline & Incierta & 6 & $3 \%$ \\
\hline & Mala & 182 & $90 \%$ \\
\hline & Regular & 14 & $7 \%$ \\
\hline \multirow{2}{*}{$\begin{array}{l}\text { De acuerdo con las medidas de contención } \\
\text { al COVID19 impuestas por las autoridades } \\
\text { (Cierre de Actividades) }\end{array}$} & No & 67 & $33 \%$ \\
\hline & $\mathrm{Si}$ & 136 & $67 \%$ \\
\hline
\end{tabular}

Elaboración: Los autores. 


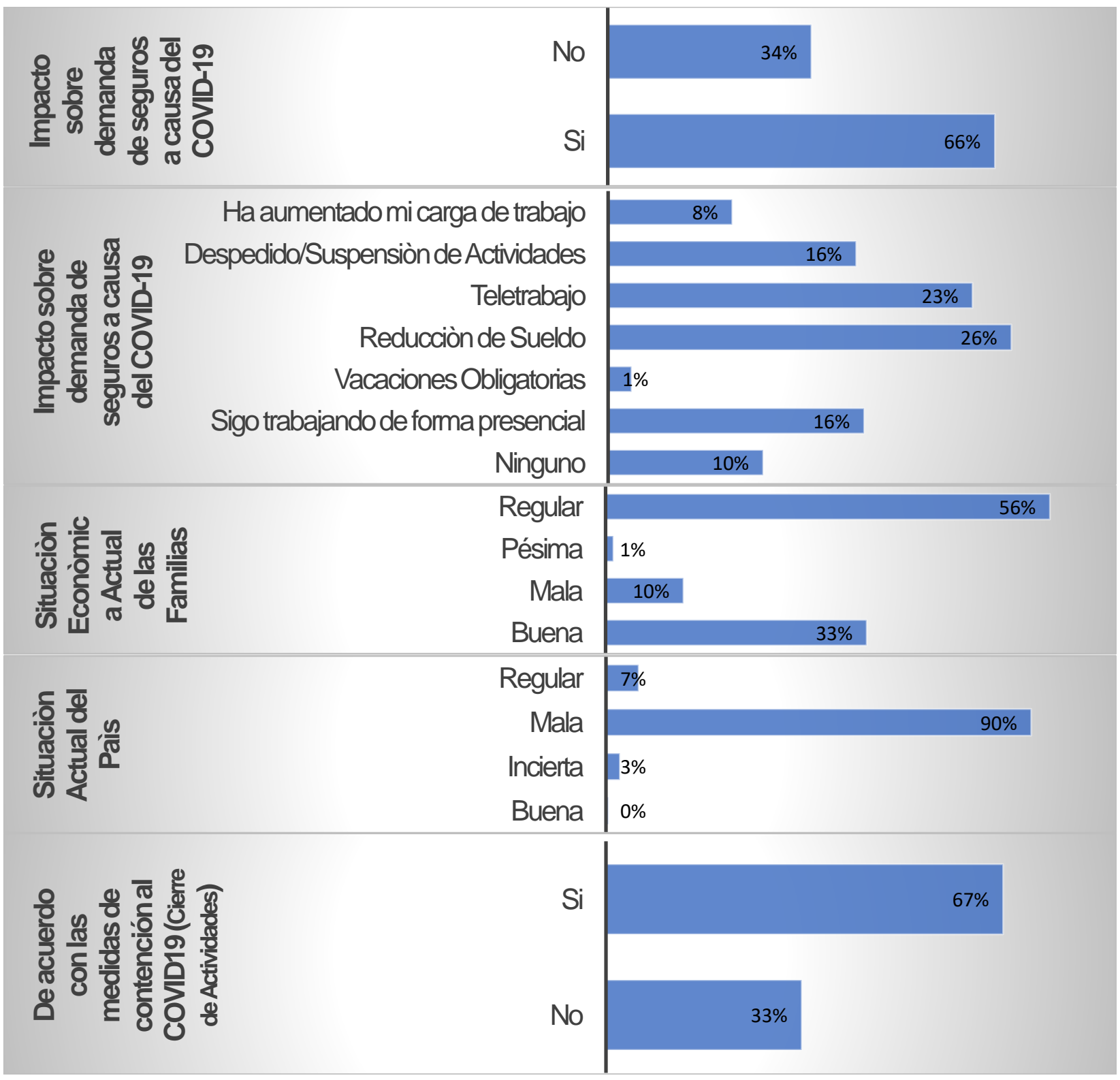

Figura 2. Resultados Variables: Impacto COVID-19. Elaboración: Los autores.

De acuerdo con la tabla y la figura 2 la pandemia ha afectado a la economía en general, un factor es la crisis económica que tenemos en el mercado asegurador, se hace un estudio coyuntural de este efecto en las personas para poder posteriormente plantear mecanismos de salida o desarrollo. Las personas indican que existe un impacto COVID- 
19 muy alto debido a cambios en sus ingresos, aumento en cargas de trabajo, teletrabajo, reducción de sueldos, despidos y/o suspensión de actividades hechos que generan graves efectos en los hábitos de los hogares y por ende a la situación económica del país.

\section{Tabla 3.}

Resultados Variables: Factores del Desarrollo del Sector Asegurador.

\begin{tabular}{|c|c|c|}
\hline $\begin{array}{l}\text { Variable: Factores del Desarrollo del } \\
\text { Sector Asegurador }\end{array}$ & Opciones de respuesta & Total \\
\hline \multirow{4}{*}{$\begin{array}{l}\text { Factores que afectan el desarrollo del } \\
\text { mercado asegurador }\end{array}$} & La Legislación y/o políticas & $4321 \%$ \\
\hline & Otros & $73 \%$ \\
\hline & Empleo/Desempleo & $5527 \%$ \\
\hline & Situación Económica de un país & $9848 \%$ \\
\hline \multirow{4}{*}{$\begin{array}{l}\text { Factores que inciden en las personas } \\
\text { para no tomar un seguro }\end{array}$} & Bajo nivel de ingresos & $6532 \%$ \\
\hline & Costos muy altos & $5728 \%$ \\
\hline & Otros & $31 \%$ \\
\hline & Poca cultura de seguros & $7838 \%$ \\
\hline \multirow{3}{*}{$\begin{array}{l}\text { Percepción Situación Económica del } \\
\text { País en } 6 \text { meses futuros }\end{array}$} & Buena & $10 \quad 5 \%$ \\
\hline & Igual & $9346 \%$ \\
\hline & Mala & $10049 \%$ \\
\hline
\end{tabular}

Elaboración: Los autores. 


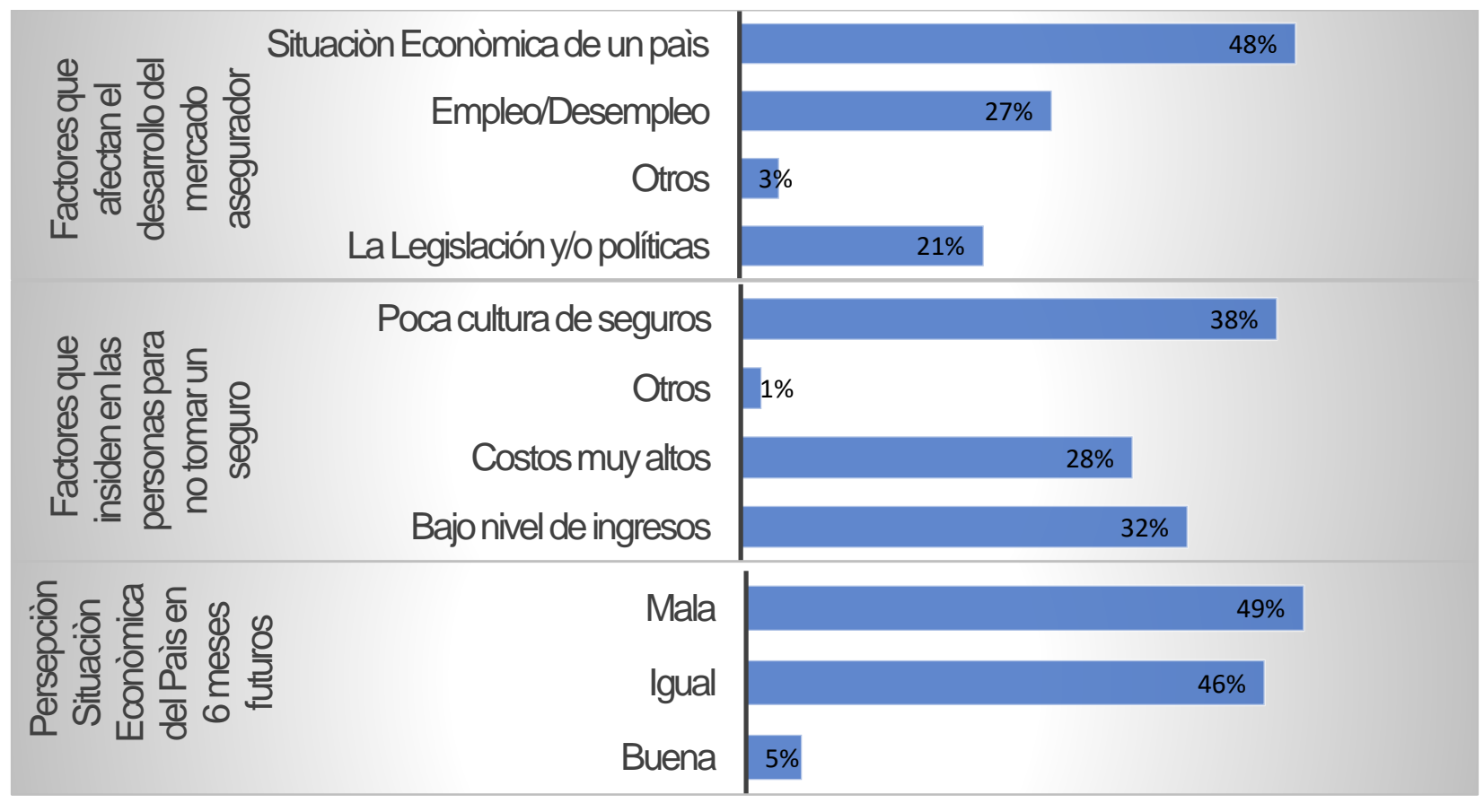

Figura 3. Resultados Variables: Factores del Desarrollo del Sector Asegurador. Elaboración: Los autores.

De acuerdo con la tabla y la figura 3, la situación económica del país y de las familias son factores determinantes que afectan el desarrollo del mercado asegurador, a esto le sigue el factor del desempleo y las legislaciones politicas, es decir, para que el mercado asegurador pueda tener un horizonte favorable debe ir de la mano con un sustento legislativo que mejore la cultura de seguros en el país como sucede en otros países del mundo. Las personas investigadas piensan que por falta de cultura no hay contrataciòn de un seguro, siendo esto una oportunidad de crecimiento, otros indican que asegurarse es muy costoso pues si tuvieran la necesitad de reducir un gasto lo primero que considerarían es la eliminación del seguro, existiendo otra ocasión de captar o afianzar clientes.

Se confirma entonces con la investigación realizada por (Cevallos-Villacis, 2012), que la evolución del mercado asegurador tiene que ver mucho con el crecimiento de la economía de un pais, las personas a quienes se estudia están dentro de un rango 
considerable para tener la responsabilidad de querer asegurar y cubrir ante cualquier pérdida material o humana, con esto concordamos con nuestro estudio, ya que la data expuesta anteriormente donde debemos concientizar a las personas para que no sea por obligación la contratación del seguro si no sea por sentido propio.

\section{PROPUESTA}

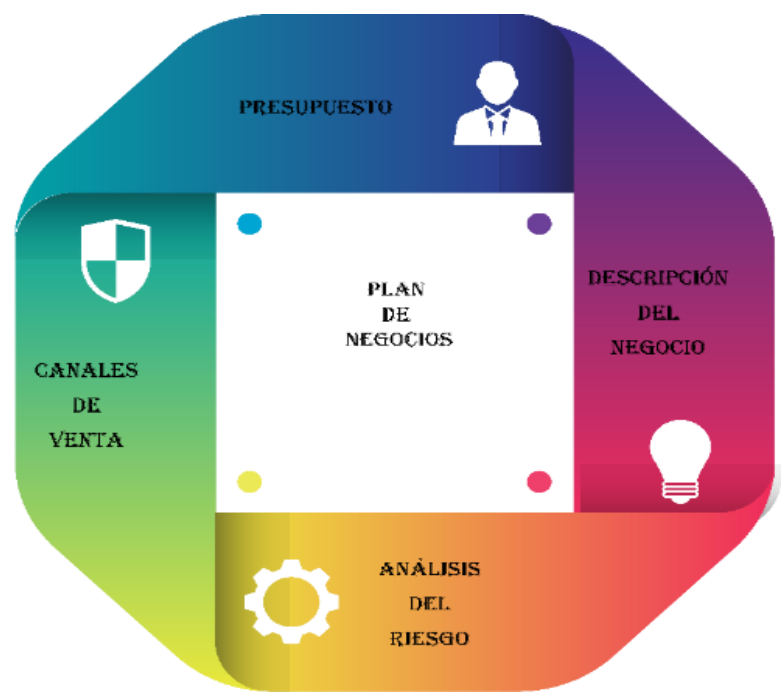

Figura 4. Esquema del Plan de Negocios. Elaboración: Los autores.

\section{Descripción del negocio}

En la tabla 4 de este cuadro se expone información complementaria de las aseguradoras, son 30 en la actualidad, pero se tomó únicamente para el análisis el top. 5 de las mejores. 
Tabla 4.

Ranking de las aseguradoras.

\begin{tabular}{|c|c|c|c|c|c|c|}
\hline \multirow[b]{2}{*}{ Compañías } & \multirow[b]{2}{*}{$\begin{array}{l}\text { Localización y } \\
\text { Fecha de } \\
\text { Constitución }\end{array}$} & \multicolumn{3}{|c|}{$\begin{array}{c}\text { Ranking En } \\
\text { Prima Neta } \\
\text { Emitida } \\
\end{array}$} & \multirow{2}{*}{ 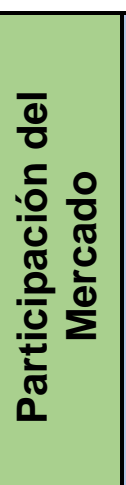 } & \multirow[b]{2}{*}{$\begin{array}{l}\text { Productos que } \\
\text { Comercializan }\end{array}$} \\
\hline & & $\begin{array}{l}\bar{\pi} \\
\frac{\pi}{0} \\
\frac{0}{0} \\
0 \\
\frac{\pi}{0} \\
\frac{\pi}{2}\end{array}$ & 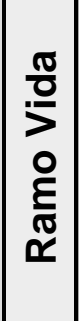 & 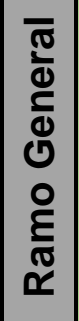 & & \\
\hline $\begin{array}{l}\text { Seguros } \\
\text { Sucre S.A. }\end{array}$ & $\begin{array}{l}\text { Ecuatoriana, } \\
\text { fundada en } \\
\text { Guayaquil, el } \\
26 / 10 / 1944\end{array}$ & 1 & 3 & 1 & $17 \%$ & $\begin{array}{c}\text { Individual: Rueda Segura, } \\
\text { Agrícola, mi Seguro. } \\
\text { Colectivo: Incendio y } \\
\text { Líneas Aliadas, entre } \\
\text { otros. } \\
\end{array}$ \\
\hline $\begin{array}{c}\text { Chubb } \\
\text { Seguros } \\
\text { Ecuador S.A. }\end{array}$ & $\begin{array}{c}\text { Fundada en } 1882 \\
\text { (New York), con el } \\
\text { nombre de ACE } \\
\text { Límite, en el } 2016 \\
\text { adquirió el nombre } \\
\text { de Chubb y opera en } \\
54 \text { países. } \\
\end{array}$ & 2 & 4 & 3 & $9 \%$ & $\begin{array}{l}\text { Propiedad comercial y } \\
\text { personal de accidentes, } \\
\text { seguro de salud personal } \\
\text { y complementario, } \\
\text { reaseguro y seguro de } \\
\text { vida, entre otros. }\end{array}$ \\
\hline $\begin{array}{l}\text { Seguros del } \\
\text { Pichincha }\end{array}$ & $\begin{array}{c}\text { Fundada el } \\
\text { 11/0/199, con capital } \\
\text { ecuatoriano- } \\
\text { colombiano, con su } \\
\text { matriz en Quito y } \\
\text { sucursales a nivel } \\
\text { nacional. }\end{array}$ & 3 & 1 & 21 & $8 \%$ & $\begin{array}{l}\text { Individuales: Hogar, } \\
\text { pichincha seguro, mi } \\
\text { familia, para mí, plus } \\
\text { Colectivos: Desgravamen } \\
\text { Consumo, Hipotecarios, } \\
\text { seguro empresariales } \\
\text { (vida y accidentes } \\
\text { personales), entre otros. }\end{array}$ \\
\hline Equinoccial & $\begin{array}{c}\text { Ecuatoriana fundada } \\
\text { en 1973, con su } \\
\text { matriz en Quito y } \\
\text { tiene varias } \\
\text { sucursales a nivel } \\
\text { nacional. } \\
\end{array}$ & 4 & 17 & 2 & $8 \%$ & $\begin{array}{l}\text { Fianzas, Mascotas, } \\
\text { Vehículos, Deporte, auto } \\
\text { seguro, entre otros. }\end{array}$ \\
\hline
\end{tabular}




\begin{tabular}{|c|c|c|c|c|c|c|}
\hline $\begin{array}{c}\text { AIG } \\
\text { Metropolitana }\end{array}$ & $\begin{array}{l}\text { Establecida en } \\
\text { Ecuador en el año } \\
\text { 1969, en la ciudad } \\
\text { de Guayaquil, en el } \\
\text { año de } 1990 \text { se } \\
\text { denomina AIG. }\end{array}$ & 5 & 5 & 5 & $6 \%$ & $\begin{array}{c}\text { Individual: Vehículos, } \\
\text { Hogar, Vida y Asistencia } \\
\text { Médica, Accidentes } \\
\text { Personales, Viaje } \\
\text { AIG/Colectivos: Líneas } \\
\text { Financieras, Pymes, } \\
\text { Aviación, Ambiental, entre } \\
\text { otros. }\end{array}$ \\
\hline
\end{tabular}

Fuente: Superintendencia de Compañias, Valores y Seguros (2020).

\section{Análisis del riesgo}

Se expone mediante una matriz de riesgos IPERC (Identificación de Peligros y Evaluación de Riesgos) para poder identificar, analizar y evaluar los peligros existentes. A continuación, se indica el proceso de calificación que utilizaremos para determinar el índice de magnitud del riesgo que se realiza mediante el cálculo de Probabilidad por Consecuencia y con los índices determinar el nivel crítico en el que se encuentran las aseguradoras.

Tabla 5.

Matriz de Riesgos.

\begin{tabular}{|r|l|l|}
\hline \multicolumn{3}{|c|}{ Evaluación de Riesgos } \\
\hline Nivel & Probabilidad & Consecuencia \\
\hline 1 & Bajo & Bajo \\
\hline 2 & Medio & Medio \\
\hline 3 & Alto & Alto \\
\hline
\end{tabular}

\begin{tabular}{|c|c|c|c|c|c|c|c|c|}
\hline \multicolumn{9}{|c|}{ MATRIZ DE RIESGOS } \\
\hline \multirow{3}{*}{ ì } & \multirow{3}{*}{ 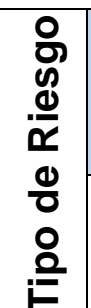 } & \multirow{3}{*}{$\begin{array}{c}\text { Identificación } \\
\text { Riesgo }\end{array}$} & \multirow{3}{*}{$\begin{array}{l}\text { Análisis } \\
\text { Efecto }\end{array}$} & \multirow{3}{*}{ 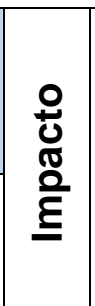 } & \multirow{3}{*}{ 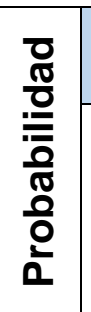 } & \multicolumn{3}{|c|}{$\begin{array}{c}\text { Evaluación del } \\
\text { Riesgo }\end{array}$} \\
\hline & & & & & & 윽 & Sel & idad \\
\hline & & & & & & 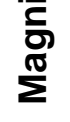 & Valor & Nivel \\
\hline
\end{tabular}




\begin{tabular}{|c|c|c|c|c|c|c|c|c|}
\hline \multirow[t]{2}{*}{1} & \multirow{2}{*}{ 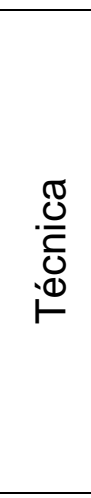 } & $\begin{array}{c}\text { Una estimación } \\
\text { incorrecta del } \\
\text { negocio al momento } \\
\text { de tarificar costos y } \\
\text { primas }\end{array}$ & $\begin{array}{c}\text { Dado cobro } \\
\text { insuficiente, en un } \\
\text { siniestro no podrá } \\
\text { cubrir los valores, } \\
\text { usando su capital } \\
\text { propio. }\end{array}$ & 3 & 2 & 6 & 3 & 온 \\
\hline & & $\begin{array}{l}\text { Provisión incorrecta } \\
\text { de reservas técnicas }\end{array}$ & $\begin{array}{l}\text { Por catástrofes, } \\
\text { pérdidas múltiples, } \\
\text { pandemias, cambio } \\
\text { ambiental. }\end{array}$ & 3 & 2 & 6 & 3 & 온 \\
\hline 2 & $\begin{array}{l}\text { 을 } \\
\text { गु } \\
\frac{0}{0} \\
\sum\end{array}$ & $\begin{array}{l}\text { Competitividad en } \\
\text { los costos }\end{array}$ & $\begin{array}{c}\text { Por cumplir metas } \\
\text { de venta, } \\
\text { competencia } \\
\text { exagerada sin } \\
\text { tarifas adecuadas. }\end{array}$ & 3 & 3 & 9 & 3 & $\frac{\text { 원 }}{4}$ \\
\hline \multirow[t]{2}{*}{3} & \multirow{2}{*}{ 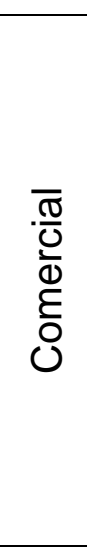 } & Fraudes & $\begin{array}{c}\text { Generar clientes } \\
\text { ficticios, o } \\
\text { emisiones sin } \\
\text { cumplir requisitos } \\
\text { de suscripción, por } \\
\text { comisiones. }\end{array}$ & 2 & 1 & 2 & 1 & $\stackrel{\circ}{\frac{0}{\widetilde{N}}}$ \\
\hline & & $\begin{array}{l}\text { Colusión para pago } \\
\text { de Siniestros }\end{array}$ & $\begin{array}{l}\text { Negociar con un } \\
\text { agente de la } \\
\text { aseguradora, o con } \\
\text { terceros a cambio } \\
\text { de un porcentaje. }\end{array}$ & 2 & 1 & 2 & 1 & . \\
\hline 4 & 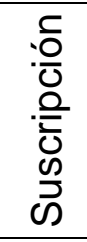 & $\begin{array}{c}\text { Cancelación de } \\
\text { Pólizas }\end{array}$ & $\begin{array}{l}\text { Pólizas que no } \\
\text { pueden ser } \\
\text { pagadas }\end{array}$ & 3 & 2 & 6 & 3 & $\frac{\text { 원 }}{4}$ \\
\hline 5 & 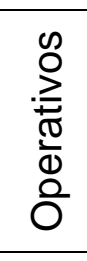 & $\begin{array}{l}\text { Empresas } \\
\text { Reaseguradoras } \\
\text { con dificultades } \\
\text { financieras }\end{array}$ & $\begin{array}{l}\text { No podrán cubrir } \\
\text { siniestros de } \\
\text { grandes por no } \\
\text { tener la solvencia } \\
\text { suficiente } \\
\end{array}$ & 2 & 1 & 2 & 2 & $\frac{0}{\frac{0}{0}}$ \\
\hline & & Calificación Ge & eeral del Riesgo & & & & 2,286 & Medic \\
\hline
\end{tabular}

Elaboración: Los autores. 


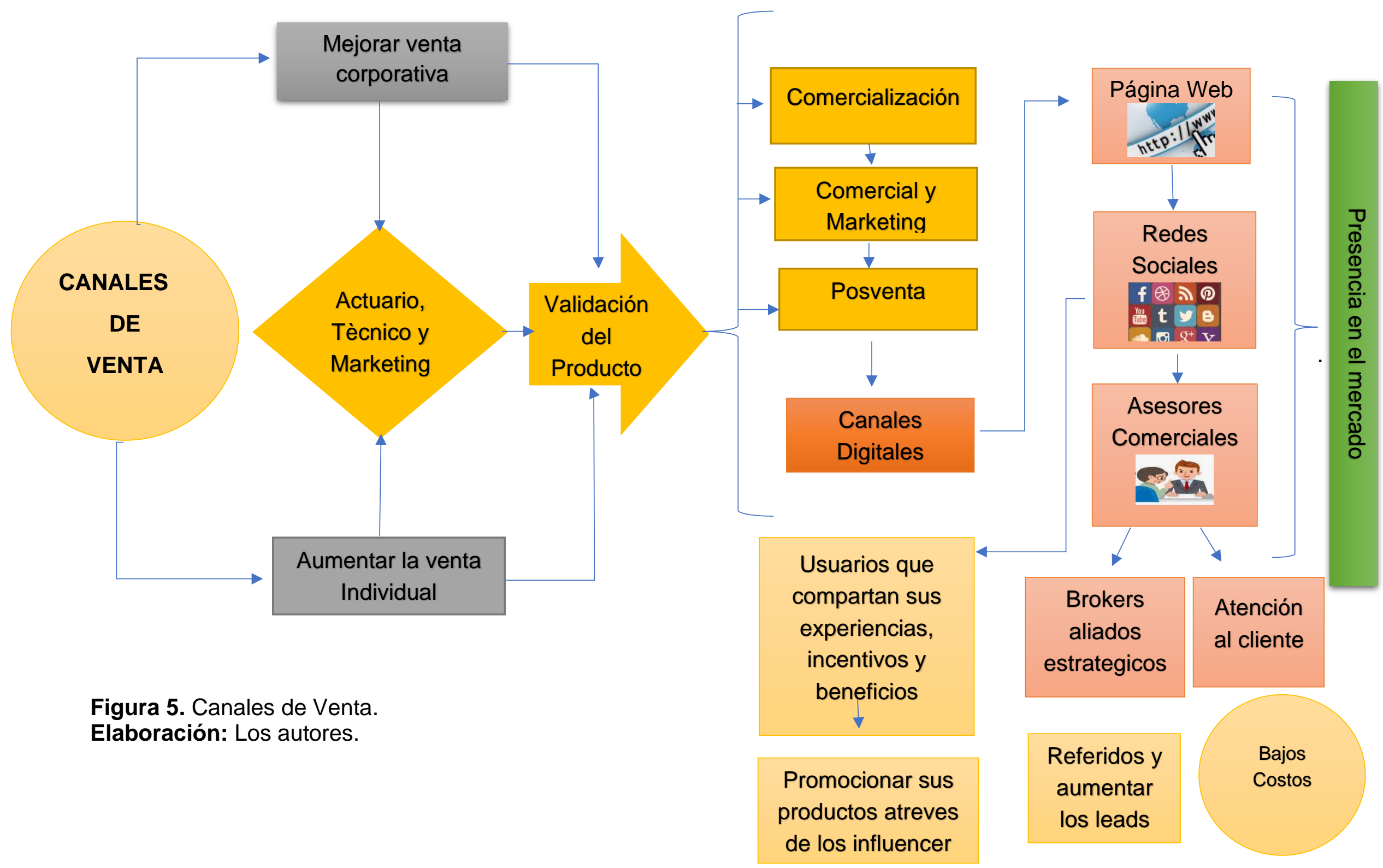




\begin{tabular}{|c|c|c|c|c|c|c|c|c|}
\hline \multicolumn{9}{|c|}{ PRESUPUESTO } \\
\hline $\begin{array}{l}\frac{\pi}{2} \\
\frac{\pi}{\pi} \\
\frac{0}{2} \\
8 \\
0\end{array}$ & 宅 & 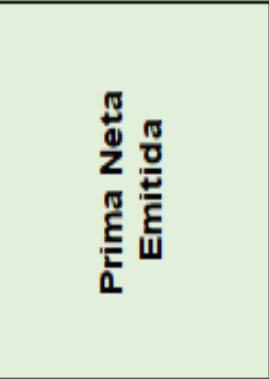 & 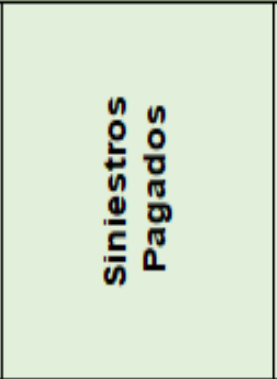 & 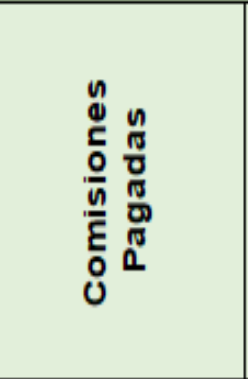 & 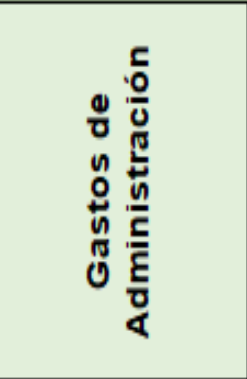 & 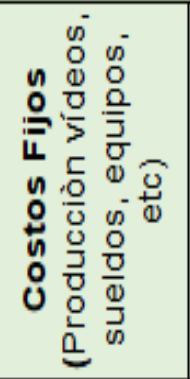 & 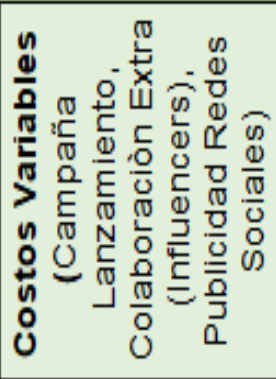 & 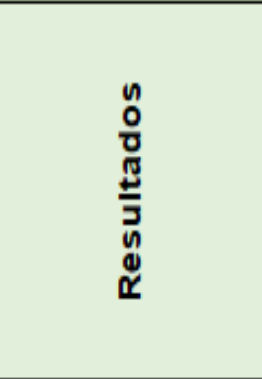 \\
\hline \multirow{3}{*}{ Sucre } & 2020 & $\$ 282.671 .566,36$ & $\$ 92.387 .553,85$ & $\$ 4.010 .584,25$ & $\$ 22.305 .607,12$ & $\$ \quad-$ & $\$$ & $\$ 163.967 .821,14$ \\
\hline & 2021 Proyectado & $\$ 287.053 .115,30$ & $\$ 129.518 .309,57$ & $\$ 28.705 .311,53$ & $\$ 22.305 .607,12$ & $\$$ & $\$$ & $\$ 106.523 .887,08$ \\
\hline & 2021 Plan & $\$ 315.758 .426,82$ & $\$ 133.403 .858,85$ & $\$ 31.575 .842,68$ & $\$ 22.305 .607,12$ & $\$ 50.000,00$ & $20.000,00$ & $\$ 128.403 .118,17$ \\
\hline \multirow{3}{*}{ Chubb } & 2020 & $\$ 153.267 .871,57$ & $\$ 53.569 .874,44$ & $\$ 8.343 .713,38$ & $\$ 23.363 .796,14$ & $\$ \quad-$ & - & $\$ 67.990 .487,61$ \\
\hline & 2021 Proyectado & $\$ 152.564 .709,03$ & $\$ 49.976 .641,43$ & $\$ 15.256 .470,90$ & $\$ 23.363 .796,14$ & $\$ \quad-$ & $\$$ & $\$ 63.967 .800,56$ \\
\hline & 2021 Plan & $\$ 167.821 .179,93$ & $\$ 51.475 .940,67$ & $\$ 16.782 .117,99$ & $\$ 23.363 .796,14$ & $\$ 50.000,00$ & $20.000,00$ & $\$ 76.129 .325,13$ \\
\hline \multirow{3}{*}{ Pichincha } & 2020 & $\$ 141.877 .663,47$ & $\$ 86.745 .648,05$ & $\$ 19.652 .353,84$ & $\$ 11.636 .739,10$ & $\$-$ & - & $\$ 23.842 .922,48$ \\
\hline & 2021 Proyectado & $\$ 136.353 .509,60$ & $\$ 59.548 .863,60$ & $\$ 13.635 .350,96$ & $\$ 11.636 .739,10$ & $\$$ & $\$$ & $\$ 51.532 .555,94$ \\
\hline & 2021 Plan & $\$ 149.988 .860,55$ & $\$ 61.335 .329,51$ & $\$ 14.998 .886,06$ & $\$ 11.636 .739,10$ & $\$ 50.000,00$ & $20.000,00$ & $\$ 61.947 .905,89$ \\
\hline \multirow{3}{*}{ Equinoccial } & 2020 & $\$ 129.706 .465,81$ & $\$ 62.742 .982,99$ & $\$ 16.187 .986,73$ & $\$ 19.364 .339,79$ & $\$ \quad-$ & $\$$ & $\$ 31.411 .156,30$ \\
\hline & 2021 Proyectado & $\$ 146.849 .996,24$ & $\$ 67.693 .656,04$ & $\$ 14.684 .999,62$ & $\$ 19.364 .339,79$ & $\$$ & $\$$ & $\$ 45.107 .000,79$ \\
\hline & 2021 Plan & $\$ 161.534 .995,86$ & $\$ 69.724 .465,72$ & $\$ 16.153 .499,59$ & $\$ 19.364 .339,79$ & $\$ 50.000,00$ & $20.000,00$ & $\$ 56.222 .690,77$ \\
\hline \multirow{3}{*}{ AIG } & 2020 & $\$ 109.086 .748,93$ & $\$ 45.748 .852,20$ & $\$ 12.375 .124,73$ & $\$ 11.823 .584,20$ & $\$ \quad-$ & - & $\$ 39.139 .187,80$ \\
\hline & 2021 Proyectado & $\$ 107.442 .373,74$ & $\$ 45.877 .816,08$ & 10744237,37 & $\$ 11.823 .584,20$ & $\$$ & $\$$ & $\$ 38.996 .736,09$ \\
\hline & 2021 Plan & $\$ 118.186 .611,12$ & $\$ 47.254 .150,56$ & $\$ 11.818 .661,11$ & $\$ 11.823 .584,20$ & $\$ 50.000,00$ & $20.000,00$ & $\$ 47.220 .215,24$ \\
\hline
\end{tabular}

Figura 6. Presupuesto.

Fuente: Superintendencia de Compañías, Valores y Seguros (2020). 


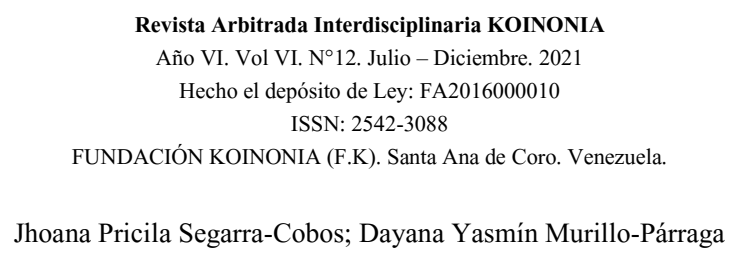

\section{CONCLUSIONES}

Dentro del crecimiento económico de un país el seguro es parte fundamental de sostenibilidad que ayuda a cubrir la pérdida financiera por la eventualidad de un siniestro, por eso para pocos individuos es una inversión y para otros un gasto que depende de cada una de las necesidades, el seguro ha cambiado y evoluciona notablemente ya que poco a poco ha ido aumentando la cultura de obtener un seguro, aprovechando para tener mayor productividad, crecimiento y participación en el mercado.

El método utilizado de la encuesta nos ayudó a identificar cada una de las variables a ser analizadas, para tener claro las estrategias a plantear.

La propuesta planteada nos ayudó a determinar que todas las empresas deben estar preparadas para hacer cambios, y sino, están preparadas simplemente con el paso del tiempo desaparecerán ya que la tecnología cada día evoluciona y da grandes pasos, todo se tiene que diversificar desde la digitalización de sus procesos hasta la emisión en línea. Cada una de las encuestas realizadas nos sirvió de guía para poder conocer la situación actual de la sociedad en general, la crisis que estamos atravesando y que tanto de participación tiene un seguro en el mercado del país.

Crear un plan mediante canales de venta ayuda a concientizar a la sociedad sobre la importancia que tiene a la hora de elegir un seguro, costos, primas, beneficios y otros, el objetivo de este es aumentar ventas y presencia en el mercado, deben innovar con la tecnología que tenemos y potenciar las herramientas que disponemos para lograr cumplir los objetivos.

\section{FINANCIAMIENTO}

No monetario.

\section{AGRADECIMIENTO}

A la Jefatura de Posgrados de la Universidad Católica de Cuenca por el apoyo permanente a la investigación. 


\section{REFERENCIAS CONSULTADAS}

Ancos-Franco, H. (2015). Industria del seguro y desarrollo sostenible. Principios de Aseguramiento Responsable[Insurance industry and sustainable development. Principles of Responsible Underwriting]. Madrid: Universidad Complutense Madrid. https://eprints.ucm.es/id/eprint/48701/

Andía-Valencia, W., \& Paucara-Pinto, E. (2013). Los planes de negocios y los proyectos de inversión: similitudes y diferencias [Business plans and investment projects: similarities and differences]. Industrial Data, 16(1),80-84.

Andrade-Granja, L. (2016). El Mercado Asegurador Ecuatoriano, Panorama, Futuro e Implementaciones frente a la Normativa inscrita en el nuevo còdigo monetario [The Ecuadorian Insurance Market, Panorama, Future and Implementation of the Regulations included in the new monetary code]. Quito: Universidad Internacional del Ecuador. http://repositorio.uide.edu.ec/handle/37000/1076

Argudo-Tello, K., Erazo Álvarez, J., \& Narváez Zurita, C. (2019). Evaluación de Control Interno en Riesgos Estratégicos para la Dirección de Planificación de la Universidad de Cuenca [Evaluation of Internal Control in Strategic Risks for the Planning Department of the University of Cuenca]. Revista Arbitrada Interdisciplinaria Koinonía, 4(1), 67-96. http://dx.doi.org/10.35381/r.k.v4i1.372

Bermudez-Barrezueta, N. (2018). Panorama del mercado asegurador asesores productores de seguros y peritos en el Ecuador [Overview of the insurance market insurance producers' and adjusters' advisors in Ecuador]. Cuenca: Superintendencia de Compañias, Valores y Seguros. https://n9.cl/nghc9

Cardona, E. (2019). Aporte de los empresarios al desarrollo del país, la mirada de Efrén Cardona [The contribution of businessmen to the country's development, the view of Efren Cardona]. Obtenido de https://n9.cl/24tqc

Castelán-Valdivia, A., \& Oros-Mendéz, L. (2011). Importancia de un Plan de Negocio [Importance of a Business Plan]. México: Servicios Académicos Intercontinentales. Obtenido de https://n9.cl/37d9u

Cevallos-Villacis, A. E. (2012). Análisis de la evolución del mercado de seguros de Guayaquil y su incidencia en la economía [Analysis of the evolution of Guayaquil's insurance market and its impact on the economy]. Guayaquil: Universidad Catolica Santiago de Guayaquil. http://repositorio.ucsg.edu.ec/handle/3317/1446 
Coronel-Pérez, V, \& Buñay-Cantos, J. (2018). Gestión de los seguros ante desastres naturales en el Ecuador [Insurance management in natural disasters in Ecuador]. Revista Universidad y Sociedad, 10(4), 199-206.

Curiosfera. (2021). Historia de los Seguros-Origen y Evolución [History of insurance Origin and evolution]. Obtenido de https://n9.cl/5tled

Erazo-Álvarez, J., \& Narváez-Zurita, C. (2020). Medición y gestión del capital intelectual en la industria del cuero - calzado en Ecuador [Measurement and management of intellectual capital in the leather industry - footwear in Ecuador]. Revista Arbitrada Interdisciplinaria Koinonía, 5(9), 437-467. http://dx.doi.org/10.35381/r.k.v5i9.662

Galdeano-Larisgoitia, I., \& Pedraz-González, R. (2019). Seguros sostenibles [Sustainable insurance]. Obtenido de https://acortar.link/oVNXp

Garzón-Castrillon, M., \& Ibarra-Mares, A. (2014). Revisión sobre la Sostenibilidad Empresarial [Corporate Sustainability Review]. Revista de estudios avanzados y liderazgo. https://acortar.link/bhlCk

Gestión. (2020). La Tendencia Aseguradora empieza a cambiar en el pais [Insurance trend begins to change in the country]. Obtenido de https://n9.cl/u6c1p

Heizer, J., \& Render, B. (2009). Administración de Operaciones [Operations Management]. México: Pearson Education, Inc.

Jiménez, A. (2020). Roles de acción del sector asegurador en la sostenibilidad [Action roles of the insurance sector in sustainability]. Revista Fasecolda.: https://acortar.link/16ONH

Jouvin-Aráuz, C., \& Rodríguez-Murillo, C. (2008). Impacto de las Compañias de Seguros en el Ecuador: Evolución e Influencia en la Economía del País[The Impact of Insurance Companies in Ecuador: Evolution and Influence on the Country's Economy]. Guayaquil: Escuela Superior Politecnica del Litoral. http://www.dspace.espol.edu.ec/handle/123456789/10393

Koontz, H., Weihrich, H., \& Cannice, M. (2012). Administración una perspectiva global y empresarial [Management a global and business perspective]. México: McGrawHill.

La Junta Bancaria. (2012). Resolución NO. JB-2012-2154 [Resolution NO. JB-20122154]. Obtenido de https://n9.cl/no1yi 
León-Alvear, R., \& León-Alvear, M. (2019). La importancia y cultura en los seguros privados [The importance and culture of private insurance]. http://www.dspace.uce.edu.ec/handle/25000/21022

Macedo, B. (2005). El concepto de sostenibilidad [The concept of sustainability]. Santiago: Organización de las Naciones Unidas para la Educación, la Ciencia y la Cultura. https://n9.cl/sttpb

Manzano-Martos, A. (2012). Claves del Seguro Español: Una aproximaciòn a la Historia del Seguro en España[Claves del Seguro Español (Keys to Spanish Insurance) an approach to the History of Insurance in Spain]. Madrid: Fundaciòn Mapfre. https://n9.cl/os41f

Martínez-Cañon, J. (2015). La importancia del emprendimiento para la empresa Barcelona Activa [The importance of entrepreneurship for the company Barcelona Activa]. Colombia: Universidad Santo Tomas. https://n9.cl/3s0zg

Mayer-Granados, E., Blanco-Jiménez, F., Alonso-Neira, M., \& Charles-Coll, J. (2020). Emprendimiento y crecimiento económico: El sistema mexicano de incubadoras de negocios [Entrepreneurship and economic growth: The Mexican system of business incubators]. Revista de Ciencias Sociales (Ve), vol. XXVI, 107-127.

Moyano-Castillejo, L. (2015). Plan de Negocios [Business Plan]. Lima,Perú: MACRO. Obtenido de https://n9.cl/qtwl

Outreville, J.F. (2013), The Relationship Between Insurance and Economic Development: 85 Empirical Papers for a Review of the Literature. Risk Management and Insurance Review, 16: 71-122. https://doi.org/10.1111/j.1540-6296.2012.01219.x

Primicias. (2019). La importancia de la productividad en el crecimiento económico [The importance of productivity in economic growth]. Obtenido de https://n9.cl/mto6

Ranis, G., \& Stewart, F. (2002). Crecimiento económico y desarrollo humano en América Latina [Economic growth and human development in Latin America]. Revista CEPAL Nro.78, 7-24. https://n9.cl/2lgba.

Rivadeneira-Hermida, M., Erazo-Álvarez, J., Bermeo-Pazmiño, K., \& CisnerosQuintanilla, D. (2021). Cambios administrativos y organizativos como propuesta emergente en Pandemia [Administrative and organizational changes as an emerging proposal in Pandemic]. CIENCIAMATRIA, 7(12), 782-806. https://doi.org/10.35381/cm.v7i12.449 
Revista Arbitrada Interdisciplinaria KOINONIA

Año VI. Vol VI. N 12 . Julio - Diciembre. 2021

Hecho el depósito de Ley: FA2016000010

ISSN: $2542-3088$

FUNDACIÓN KOINONIA (F.K). Santa Ana de Coro. Venezuela.

Jhoana Pricila Segarra-Cobos; Dayana Yasmín Murillo-Párraga

Sabater-Castro, A. (2017). El desarrollo del sector asegurador y el crecimiento económico: un análisis empírico para 47 países [Development of the insurance sector and economic growth: an empirical analysis for 47 countries]. Economía y Sociedad, 22(52), 88-109. https://dx.doi.org/10.15359/eys.22-52.5

Saltos, F. (2016). Importante Evoluciòn del Mercado de Seguros [Important Developments in the Insurance Market]. Recuperado de https://n9.cl/bwe0j.

Sánchez-Sumelzo, N. (2012). La sostenibilidad en el sector empresarial [Sustainability in the business sector]. Catalunya: UPC Universitat Politécnica de Catalunya. https://n9.cl/re8w

Superintendencia de Compañias, Valores y Seguros. (2020). Ranking de Aseguradoras [Ranking of Insurance Companies]. Recuperado de https://n9.cl/meix

UNESPA. (2020). Las 5 cosas que hace el seguro por la sostenibilidad [The 5 things insurance does for sustainability]. Obtenido de https://acortar.link/m8j7F

Vidal-Beltrán, K., Erazo Álvarez, J., \& Narváez Zurita, C. (2019). La lógica difusa como herramienta de evaluación financiera de proyectos de inversion [Fuzzy logic as a financial evaluation tool for investment projects]. Revista Arbitrada Interdisciplinaria Koinonía, 4(1), 309-348. http://dx.doi.org/10.35381/r.k.v4i1.460

Viniegra, S. (2007). Entendiendo el Plan de Negocios [Understanding the Business Plan]. Obtenido de https://n9.cl/z3jhm

Zamora-Boza, C. (2018). La importancia del emprendimiento en la economía: el caso de Ecuador [The importance of entrepreneurship in the economy: the case of Ecuador]. Espacios, (39), 7. https://n9.cl/g7cdx 